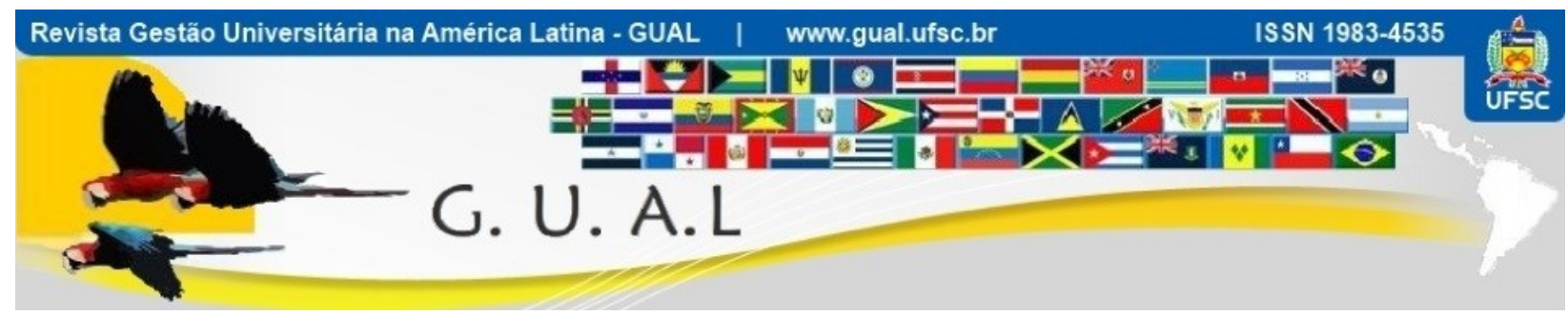

DOI: http://dx.doi.org/10.5007/1983-4535.2017v10n4p109

\title{
BENEFÍCIOS E DESAFIOS NA IMPLANTAÇÃO DA AUDITORIA BASEADA EM RISCO EM INSTITUIÇÕES FEDERAIS DE ENSINO
}

\section{BENEFITS AND CHALLENGES OF RISK-BASED AUDIT IMPLEMENTATION AT FEDERAL EDUCATION INSTITUTIONS}

Guilherme Caetano de Brito, Mestre Universidade Federal de Goiás - UFG guilhermecaetanobrito@gmail.com

Daiana Paula Pimenta, Doutora Universidade Federal de Goiás - UFG daiana-pimenta@hotmail.com

Eliane Moreira Sá de Souza, Pós-Doutora Universidade Federal de Goiás - UFG eliane.mss@hotmail.com

Alethéia Ferreira da Cruz, Doutora Universidade Federal de Goiás - UFG aletheiacruz@yahoo.com.br

Recebido em 25/novembro/2016

Aprovado em 16/outubro/2017

Sistema de Avaliação: Double Blind Review

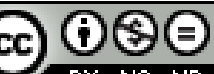

Esta obra está sob uma Licença Creative Commons Atribuição-Uso. 


\title{
RESUMO
}

A administração pública brasileira passou por várias reformas com objetivo de modernização da gestão. Com a Reforma Gerencial passou a buscar eficiência, gestão por resultados e descentralização das atividades. Como consequência, o controle interno deixou de focar no formalismo dos atos e direcionou suas atividades, de forma descentralizada pelas unidades de auditoria interna, para a avaliação do alcance dos objetivos e da gestão de riscos das organizações públicas. No âmbito do Ministério da Educação, há instituições federais de ensino superior (IFES) que adotam a metodologia de Auditoria Baseada em Riscos (ABR) há alguns anos, entretanto, não há estudos sobre os impactos resultantes da adoção da metodologia ou, ainda, sobre a melhor forma de desenvolver o processo de implantação. $\mathrm{O}$ objetivo deste trabalho é identificar os benefícios e desafios na implantação da ABR nas IFES. Os dados foram obtidos por meio de questionário aplicado a auditores internos das IFES e, em seguida, tratados estatisticamente com a utilização da técnica de análise fatorial para extrair fatores que representem grupos de benefícios e desafios na implantação da ABR. Foram extraídos dois fatores que representam benefícios e três fatores que representam desafios na implantação da ABR.

Palavras-chave: Auditoria Interna. Auditoria Baseada em Riscos. Benefícios. Desafios.

\begin{abstract}
The Brazilian public administration have experienced several reforms to improve government organization and management. Among these, The Management Reform allowed to pursue efficiency, performance-based management and tasks decentralization. Hence, internal controls shifted from focusing on the formalism of the acts to conducting public activities through the evaluation of the achievement of objectives and the risk management of public organizations in a decentralized manner by internal audit units, called Risk Based Audit (ABR). In that regard, some federal institutions of education (IFES) have adopted this methodology, however, no studies explored the impacts of performing this approach or, the best way to develop the process. Thus, the aim of this paper is to identify the benefits and challenges in the implementation of ABR in IFES. The data were obtained through a survey that was applied to internal auditors of the IFES and statistically treated using the factorial analysis technique to identify groups of benefits and challenges in the implementation of ABR. By extracting factors of ABR, the research showed that two factors represent benefits and three factors describe challenges in the implementation of $A B R$.
\end{abstract}

Keywords: Internal Audit. Risk-based Audit. Benefits. Challenges. 


\section{INTRODUÇÃO}

A administração pública brasileira passou por diversas transformações desde o período de colonização por Portugal. A administração iniciou com características patrimonialistas, como o nepotismo e a corrupção, tendo passado pela reforma burocrática, focada no controle da legalidade e na centralização das atividades para combater a corrupção (BRESSER PEREIRA, 2001).

Após a administração burocrática se mostrar lenta e ineficiente, foi realizada a reforma gerencial, que instituiu inovações em busca da eficiência na administração pública brasileira. Dentre as principais características da administração gerencial, destacam-se a gestão por resultados e a descentralização das atividades (ABRUCIO, 2007).

A função de controle acompanhou a descentralização das atividades executadas pelo poder executivo do Governo Federal, transferindo o protagonismo do controle externo para o controle interno na Constituição Federal de 1988. A partir de 2000, a regulamentação do Sistema de Controle Interno do Poder Executivo Federal fortaleceu o papel das unidades de auditoria interna em todos os órgãos públicos federais.

Sobre a evolução do controle interno no Brasil, Castro (2008) afirma que este passou por fases e modificou seu foco ao longo dos anos. O controle interno focado nos processos prevaleceu até o fim do regime militar, sendo gradualmente substituído pelo controle focado no resultado até 2001. Após a criação da Controladoria Geral da União (CGU) e o fortalecimento das auditorias internas nos órgãos públicos, o foco passou a ser a gestão de riscos.

No âmbito internacional, o Institute of Internal Auditors (IIA) passou a incluir a avaliação da gestão de riscos entre os objetivos da auditoria interna a partir de 2004. A inclusão da gestão de riscos nas Normas Internacionais de Auditoria Interna é um marco da mudança de foco da avaliação sob a ótica dos controles internos para o foco nos riscos das atividades (CASTRO, 2008).

No setor público brasileiro, a obrigatoriedade legal de abordagem do risco nas atividades de auditoria interna surgiu apenas em 2015, por meio da Instrução Normativa $\mathrm{n}^{\circ}$ 24, de 17 de novembro de 2015, que estabelece as diretrizes para planejamento, execução, comunicação e monitoramento nas atividades de auditoria interna no poder executivo federal.

Em seguida, foi instituída a obrigatoriedade legal de adoção de medidas para a sistematização de práticas relacionadas à gestão de riscos, aos controles internos e à 


\section{BENEFÍ́CIOS E DESAFIOS NA IMPLANTAÇÃO DA AUDITORIA BASEADA EM RISCO EM \\ INSTITUIÇÕES FEDERAIS DE ENSINO \\ DOI: http://dx.doi.org/10.5007/1983-4535.2017v10n4p109}

governança corporativa nos órgãos do poder executivo, por meio da Instrução Normativa Conjunta $\mathrm{n}^{\mathrm{o}} 1$, de 10 de maio de 2016. Portanto, a gestão de riscos é tema bastante novo para a administração pública brasileira e, consequentemente, para a atividade de auditoria interna governamental.

Nesse sentido, o sucesso na implantação da auditoria baseada em riscos (ABR) está diretamente relacionada com a estrutura de gestão de riscos adotada na organização (GRIFFITHS, 2005; POMMERENING; BENCKE, 2011; PINHO; BEZERRA, 2015) e com o nível e maturidade de gestão de riscos da organização (CICCO, 2007; MADEIRA, 2010; BENLI; CELAYIR, 2014).

Apesar do recente marco normativo, novembro de 2015, para a abordagem dos riscos institucionais nas atividades de auditoria interna, alguns órgãos do poder executivo federal já utilizam a ABR há alguns anos. Diversas instituições federais de ensino superior (IFES) também desenvolvem trabalhos de auditoria interna sob a ótica dos riscos e, portanto, passaram pelo processo de implantação da metodologia de ABR. Todavia, pouco se sabe sobre o processo de implantação da ABR adotado pelas IFES, quais foram os principais desafios identificados durante o processo e quais os principais benefícios observados após a adoção.

Acredita-se que a implantação da ABR é uma importante ferramenta de gestão universitária, que cada vez mais exige competências e habilidade de seus líderes a fim de gerar valor para todas as partes interessadas, ou seja, para alunos e clientes, colaboradores, parceiros, mantedores, acionistas, sociedade, entre outros (COLOMBO; RODRIGUES, 2011).

Nesse sentido, este trabalho pretende responder à seguinte questão: Quais são os principais benefícios e desafios na implantação da metodologia da ABR nas IFES?

O objetivo geral deste trabalho consiste em realizar um diagnóstico acerca dos benefícios e desafios na implantação da ABR nas IFES brasileiras. Quanto aos objetivos específicos, visa-se conhecer o panorama da adoção de gestão de riscos e auditoria baseada em riscos nas IFES; e diagnosticar os principais benefícios e desafios na implantação da auditoria baseada em riscos em IFES.

O trabalho está estruturado em quatro seções além dessa introdução. Na segunda seção apresenta-se o referencial teórico, na sequência a metodologia e os resultados da pesquisa. Por fim, aduz-se as considerações finais do estudo. 


\section{ORIGEM E EVOLUÇÃO HISTÓRICA DA AUDITORIA INTERNA}

A origem da auditoria é comumente discutida entre os especialistas, apesar de não haver consenso sobre a data exata de seu surgimento. Segundo Sá (2002), há registros arqueológicos de inspeção e verificação na Suméria por volta de 4.500 a.C. Em data próxima, por volta de 4.000 a.C., afirma Ramamoorti (2003), historiadores acreditam que sistemas formais foram instituídos no Oriente Médio com objetivo de verificar o correto registro de receitas, desembolsos e arrecadação de impostos.

Boynton, Johnson e Kell (2002) destacam a preocupação com a auditoria das finanças públicas desde o Egito Antigo, onde autoridades providenciavam verificações independentes nos registros de arrecadações de impostos, enquanto na Grécia realizavam inspeções nas contas de funcionários públicos e em Roma comparavam gastos com autorizações de pagamentos.

Ramamoorti (2003) destaca também os indícios de atividade de auditoria nos sistemas de finanças públicas na Babilônia, Grécia, Império Romano e nas cidades-estado da Itália, onde os governantes estabeleceram sistemas de checagem para identificar erros de empregados incompetentes ou dispostos a cometer fraudes. Entretanto, Attie (2011) relata a origem da atividade de auditoria somente no século XI, na Inglaterra, no período em que esta dominava o comércio marítimo e expandiu seus investimentos em diversos locais e países, passando a examinar os investimentos mantidos naqueles locais.

Paralelamente ao crescimento da auditoria externa, as organizações estruturaram departamentos de auditoria interna considerados como "olhos e ouvidos" dos gestores. Sua função primária focava em proteção contra fraudes, perda de dinheiro e outros ativos, mas rapidamente o escopo da auditoria interna foi expandido para verificação de quase todas as transações financeiras (RAMAMOORTI, 2003).

A queda da bolsa de New York, em 1929, ressaltou as deficiências no controle das demonstrações contábeis das companhias americanas e, a partir da necessidade retomada da confiança dos investidores nas informações divulgadas, foi demandada maior atuação da auditoria externa e interna nas empresas (BOYNTON; JOHNSON; KELL, 2002).

Com a criação da Security and Exchange Comission - SEC, em 1934, nos Estados Unidos, a profissão do auditor foi fortalecida, pois as grandes empresas que faziam transações comerciais por meio de ações na Bolsa de Valores foram obrigadas a utilizar serviços de 
auditoria para dar maior fidedignidade às suas demonstrações financeiras (CREPALDI, 2009).

O fortalecimento da atividade de auditoria interna induziu à fundação da primeira associação profissional de auditores internos, em 1941, o The Institute of Internal Auditors (IIA), com missão de promover os valores que a auditoria interna poderia agregar à gestão, além de estabelecer normas e padrões de auditoria interna. O IIA publicou o primeiro guia, denominado "Statement of the Responsibilities of the Internal Auditor" (Declaração das Responsabilidades do Auditor Interno), em 1947.

McNamee e Selim (1998) afirmam que a primeira fase da auditoria interna, focada em revisão de procedimentos financeiros, foi encerrada em 1940. A segunda fase, com mudança de enfoque para a avaliação dos controles internos, iniciou em 1941 e predominou até os anos 1980. Segundo Ramamoorti (2003), o ambiente de negócios experimentou mudanças rápidas e revolucionárias com consequências para as organizações em todo o mundo. A maior competição global aumentou iniciativas de gestão de risco e os auditores internos foram vistos como o grupo mais qualificado de profissionais para ajudar neste processo.

McNamee e Selim (1998) afirmam que a partir dos anos 1990, as atividades das organizações passam a ser vistas como negócios baseados em riscos, provocando novas mudanças na atuação da auditoria interna, que deixa de focar na avaliação dos controles internos e passa a planejar suas ações baseada em princípios de gerenciamento de riscos. $\mathrm{O}$ foco na gestão de riscos torna-se bastante claro por meio dos objetivos e procedimentos definidos para a auditoria interna dispostos nas Normas Internacionais para a Prática Profissional de Auditoria Interna atualizadas pelo IIA, em 2004, e revisadas em 2008 e 2013.

\subsection{NORMAS DE AUDITORIA INTERNA}

O IIA divulga as Normas Internacionais para a Prática Profissional de Auditoria Interna desde 1978, sendo de 2013 a versão mais atualizada. Tais normas não têm caráter legal, mas, segundo o IIA (2013), se o auditor interno estiver proibido de seguir, por força de lei, alguma parte das normas, ainda assim é necessária a conformidade com todas as demais partes das normas, além da divulgação da particularidade da situação.

As normas fornecem um método organizado de olhar para os princípios e procedimentos que fazem a auditoria interna uma atividade única, disciplinada e sistemática (PICKETT, 2005). Além de serem importantes para os auditores internos, elas também são 


\section{BENEFÍ́CIOS E DESAFIOS NA IMPLANTAÇÃO DA AUDITORIA BASEADA EM RISCO EM \\ INSTITUIÇÕES FEDERAIS DE ENSINO \\ DOI: http://dx.doi.org/10.5007/1983-4535.2017v10n4p109}

bastante apreciadas pelos comitês de auditoria e pelos gestores por fornecer parâmetros de avaliação dos auditores internos e da atividade de auditoria interna na organização (MOELLER, 2009).

A estrutura das Normas é dividida entre Normas de Atributos, Normas de Desempenho e Normas de Implantação. Enquanto as Normas de Atributos e de Desempenho aplicam-se a todos os serviços de auditoria interna, as Normas de Implantação aplicam-se a tipos específicos de trabalhos de auditoria (IIA, 2013).

A auditoria interna deve avaliar as exposições de risco relacionadas com a governança, as operações da organização e as normas de controle interno (MOELLER, 2009). As principais áreas de risco devem ser constantemente observadas pela auditoria interna, assim como a gestão dos riscos relacionados. Caso a auditoria interna julgue que um risco assumido é inaceitável ou bastante alto, a situação deve ser discutida e acordada com os gestores da área (GRIFFITHS, 2005).

As Normas de Implantação, adicionalmente, são fornecidas para expandir as normas de Atributos e de Desempenho ao prover os requerimentos aplicáveis às atividades de consultoria (PICKETT, 2005). Especificamente para o setor público brasileiro, há normas diferentes para os poderes executivo, judiciário e legislativo, assim como há normas diferentes no âmbito federal, estadual e municipal. No presente trabalho, serão apresentadas somente as normas aplicáveis à auditoria interna no poder executivo federal.

O Manual do Sistema de Controle Interno do Poder Executivo Federal, aprovado pela Instrução Normativa $n^{0}$ 01, de 06 de abril de 2001, é o principal documento de orientação normativa para a atividade de auditoria interna no âmbito do poder executivo federal. O Capítulo $\mathrm{X}$ desta instrução normativa traz como finalidades básicas da auditoria interna o fortalecimento da gestão, a racionalização das ações de controle e o apoio aos órgãos do SCI (BRASIL, 2001).

Em 2015, as instruções normativas supracitadas foram revogadas pela publicação da Instrução Normativa $\mathrm{n}^{\mathrm{o}} 24$, de 17 de novembro de 2015, que já apresenta viés para o planejamento e execução das atividades de auditoria com foco na gestão de riscos. A importância da consideração do gerenciamento de riscos torna-se evidente na obrigatoriedade de elaboração de matriz de risco para seleção de temas a serem auditados. 


\subsection{AUDITORIA BASEADA EM RISCO}

A ABR é o desenvolvimento mais emocionante e significativo da história da profissão de auditoria interna e tem potencial para alavancar a níveis altíssimos a reputação e o valor agregado pela profissão (GRIFITHS, 2005).

Griffith (2005, p. 5) apresenta um conceito simples para a ABR: “Auditoria baseada em risco se caracteriza por ser um conjunto de processos, abordagens e metodologias que buscam focar o trabalho naquilo que realmente importa para a entidade". Cicco (2007) define a ABR como uma metodologia que fornece garantia de que o arcabouço de gestão de riscos está operando conforme requerido pelo conselho.

Segundo o IIA (2013), ABR é uma metodologia que associa a auditoria interna ao arcabouço global de gestão de riscos de uma organização. Definição corroborada por Pinho e Bezerra (2015), ao entenderem que a ABR atua emitindo opinião a respeito do tratamento dos riscos para os gestores da entidade, de modo que decisões possam ser tomadas com base nesta avaliação.

Pode-se considerar a ABR como uma evolução da auditoria tradicional. Enquanto a última tem como foco a avaliação do sistema de controle interno da organização, a primeira concentra seus esforços na avaliação da postura da administração das entidades perante os riscos. A mudança é profunda, uma vez que a auditoria deixa de ser reativa para assumir uma postura preventiva (POMMERENING; BENCKE, 2011).

A auditoria tradicional baseia-se na avaliação da entidade e dos seus controles, sendo os testes aplicados a todos os controles, objetivando inspecionar e detectar possíveis problemas na rotina da entidade. Enquanto a ABR aplica testes em processos cujos riscos foram identificados no levantamento de informações, sendo esses testes focalizados nos controles que minimizam os riscos relevantes, visando antecipar e prevenir riscos de negócios na origem (PINHO; BEZERRA, 2015).

Quantos aos benefícios de implantação da ABR, a metodologia é considerada mais eficiente porque avalia as áreas de maior risco, ao invés de uma análise exclusiva, como a área financeira, por exemplo, o que pode não representar um risco elevado (GRIFFITHS, 2005; CASTANHEIRA, 2007).

Avaliação top-down é outro benefício da ABR quando comparada à auditoria tradicional. Esta atua nas operações bases da entidade, portanto, enfocada de baixo para cima, enquanto a ABR utiliza um enfoque top-down, de cima para baixo, fazendo uma análise 


\section{BENEFÍ́CIOS E DESAFIOS NA IMPLANTAÇÃO DA AUDITORIA BASEADA EM RISCO EM \\ INSTITUIÇÕES FEDERAIS DE ENSINO \\ DOI: http://dx.doi.org/10.5007/1983-4535.2017v10n4p109}

estratégica e tática dos negócios e dos objetivos da entidade, proporcionando, com isso, um salto em valor para a auditoria (PINHO; BEZERRA, 2015).

Nesse sentido, a ABR possibilita que a auditoria interna tenha uma visão integrada da instituição em detrimento de uma visão departamentalizada, contribuindo para o alcance dos objetivos da organização, ao invés de apenas atuar no aperfeiçoamento dos controles internos de forma dispersa em cada departamento (POMMERENING; BENCKE, 2011).

Em estudo sobre a implantação da ABR no Banco do Nordeste do Brasil (BNB), Madeira (2010) identificou cinco principais aspectos de melhoria observados pelos auditores internos do BNB: eficácia do processo de auditoria; conhecimento dos controles; conhecimento dos riscos; gerenciamento das recomendações; redução dos custos do trabalho da auditoria. Conclui, por conseguinte, que a metodologia ABR possibilita ganho de eficácia nos trabalhos, aliada à perspectiva de redução nos custos de execução das auditorias.

A partir do maior conhecimento sobre os controles e riscos, é relativamente fácil de identificar os processos mais importantes da organização, possibilitando elaborar um planejamento de auditoria que priorize ações nestas atividades consideradas mais importantes (GRIFFITHS, 2005).

Os relatórios elaborados pela metodologia $\mathrm{ABR}$ são mais facilmente aceitos pelos gestores, visto que não apontam diretamente seus erros, mas apresentam uma visão mais global de toda a entidade e seus processos (CICCO, 2007).

Ao apontar medidas preventivas, em lugar de medidas corretivas, os relatórios tornamse mais agradáveis aos gestores e promovem menor atrito com os auditados e maior aproximação com a alta administração (POMMERENING; BENCKE, 2011).

Essa atuação conjunta da auditoria interna com a alta administração torna as respostas aos riscos mais eficazes e induzem ao monitoramento do processo de gestão de riscos para garantir que continue operando com alta eficácia (CICCO, 2007). A partir da metodologia ABR, o papel da auditoria interna tornar-se-á ainda mais importante na eficiência da gestão de riscos nas organizações (KARAGIORGOS et al, 2010).

A ausência de processo adequado de gestão de riscos é a principal dificuldade de implantação da ABR citada por Pinho e Bezerra (2015), Grifiths (2005) e Pommerening e Bencke (2011). Também recebe destaque a baixa maturidade de gestão de riscos como fator dificultador na implantação da ABR na instituição, pois, na falta de uma política de gestão de riscos formalmente emitida pela organização, caberá à auditoria interna realizar avaliação de 


\section{BENEFÍ́CIOS E DESAFIOS NA IMPLANTAÇÃO DA AUDITORIA BASEADA EM RISCO EM \\ INSTITUIÇÕES FEDERAIS DE ENSINO \\ DOI: http://dx.doi.org/10.5007/1983-4535.2017v10n4p109}

riscos por métodos alternativos (MADEIRA, 2010; BENLI; CELAYIR, 2014). Já Cicco (2007) chega a afirmar que só é possível implantar a ABR em organizações com nível de maturidade habilitado ou gerenciado.

Nas entidades em que a gestão de riscos não é madura, a $\mathrm{ABR}$ colabora com a sua implantação, auxiliando na identificação, medição e priorização dos riscos. Enquanto onde a gestão de riscos já está consolidada, a ABR certifica a direção da empresa de que a estrutura disponibilizada para combater os riscos está atuando de forma razoável (POMMERENING; BENCKE, 2011).

Anteriormente citada como benefício da implantação da ABR, a aproximação dos auditores internos com os gestores torna-se um desafio quando passa a reduzir a independência da função da auditoria interna (GRIFFITHS, 2005). Sobre os fatores comportamentais, Griffiths (2005) afirma que a resistência à mudança no foco das auditorias ocorre tanto com auditores internos quanto com os gestores. A natural resistência à mudança causa falta de envolvimento dos indivíduos interessados e falta de apoio da alta administração, nestes casos é recomendável a realização de reciclagens quanto à visão de riscos e controles visando a sensibilização de gestores e auditores (CICCO, 2007).

A utilização de padrões subjetivos de avaliação e a necessidade de conhecimento sobre objetivos, estratégias, mapeamento de processos e gestão de riscos exigem que os auditores sejam mais especializados e, portanto, torna a capacitação técnica dos auditores um grande desafio para a implantação da ABR (MADEIRA, 2010; POMMERENING; BENCKE, 2011).

Madeira (2010), em sua pesquisa já citada sobre a implantação da ABR no BNB, concluiu que os principais desafios à implantação da metodologia são ligados à execução das atividades de auditorias, com destaque para ausência de sistema informatizado para gerir as ações de auditoria, ausência de instrumentos e papéis de trabalho específicos para o foco em riscos e dificuldades na padronização nos trabalhos da equipe.

Por fim, a mudança para a metodologia ABR também apresenta dificuldades normativas. Borges, Diel e Fernandes (2015) citam a dificuldade de adequação aos aspectos legais vigentes nas diferentes atividades do setor público e do setor privado, enquanto Madeira (2010) cita a dificuldade de aderência às normas internas da organização e às normas internacionais de auditoria. 


\section{METODOLOGIA}

Esta pesquisa objetiva aplicar um questionário aos auditores internos para identificar os desafios e os benefícios da implantação da auditoria baseada em riscos nas instituições federais de ensino brasileiras.

A pesquisa é classificada quanto a natureza como aplicada, quantos aos objetivos como descritiva e quanto a forma de abordagem do problema é uma pesquisa quantitativa. $\mathrm{O}$ procedimento técnico adotado foi o levantamento de dados por meio de um questionário eletrônico.

\subsection{INSTRUMENTO DE PESQUISA}

O instrumento utilizado para coleta de dados foi o questionário eletrônico. Lakatos e Marconi (2003) explicam que o questionário é um instrumento de coleta de dados constituído por uma série ordenada de perguntas que deve ser respondida sem a presença do pesquisador, tendo taxa média de devolução de 25\%. Martins e Theóphilo (2009) recomendam que, no momento do encaminhamento do questionário, sejam fornecidas explicações sobre o propósito da pesquisa e suas finalidades, objetivando despertar o interesse do informante em responder o questionário.

O questionário eletrônico desta pesquisa é composto de quinze questões fechadas e segmentado em três seções. As treze primeiras questões objetivam identificar o perfil dos respondentes, as características da gestão de riscos nas instituições em que os respondentes trabalham e as características da metodologia de auditoria baseada em riscos nas instituições em que os respondentes trabalham.

As últimas duas questões objetivaram avaliar o grau de importância de benefícios e desafios na implantação da $\mathrm{ABR}$ nas organizações dos respondentes. Ambas as questões foram elaboradas com 14 atributos, a partir dos benefícios e desafios discutidos ao longo do referencial teórico deste trabalho.

\subsection{COMUNICAÇÃO COM OS INDIVÍDUOS PESQUISADORES E AMOSTRA DA PESQUISA}

O questionário eletrônico foi elaborado por meio da ferramenta "Formulários Google" e ficou disponível para respostas por 45 dias. Os indivíduos pertencentes à população, 422 servidores públicos integrantes das unidades de auditoria interna das 103 instituições federais 


\section{BENEFÍ́CIOS E DESAFIOS NA IMPLANTAÇÃO DA AUDITORIA BASEADA EM RISCO EM \\ INSTITUIÇÕES FEDERAIS DE ENSINO \\ DOI: http://dx.doi.org/10.5007/1983-4535.2017v10n4p109}

de ensino brasileiras, foram convidados a participar da pesquisa por meio dos endereços de email obtidos via pesquisa no sítio eletrônico destas instituições.

Enquanto alguns sites informam o e-mail de todos os integrantes de sua unidade de auditoria interna, a maioria informa apenas o e-mail do chefe da unidade ou o e-mail geral da unidade. Para estes últimos casos, foi solicitado ao chefe da unidade que encaminhasse o questionário aos demais integrantes da auditoria interna.

Após os procedimentos mencionados, obteve-se 127 questionários respondidos, o que corresponde a 30,09\% da população, e representa a amostra desta pesquisa. Dentre esses, 51 respondentes confirmaram a implantação da auditoria baseada em riscos em suas instituições e, portanto, responderam a última seção do questionário.

\subsection{ANÁLISE DOS DADOS}

As 13 (treze) primeiras questões do questionário, que tratam do perfil dos respondentes, gestão de riscos das IFES e características da auditoria baseada em riscos nas IFES foram analisadas por meio de frequência absoluta e relativa (FÁVERO et al, 2009). Já as duas (2) últimas questões do questionário, que se referem aos benefícios e desafios na implantação da auditoria baseada em risco, foi utilizada a análise fatorial.

Segundo Fávero et al (2009), a análise fatorial é uma técnica multivariada de interdependência que busca sintetizar as relações observadas entre um conjunto de variáveis, buscando identificar fatores comuns. Hair et al (2005) afirma que a análise fatorial pode ser utilizada para examinar as relações entre um grande número de variáveis e determinar se a informação pode ser resumida em um conjunto menor de fatores.

Se o número de variáveis é muito grande ou se há necessidade de representar melhor um número melhor de conceitos, a análise fatorial pode auxiliar na seleção de um subconjunto representativo de variáveis ou mesmo na criação de novas variáveis como substitutas das variáveis originais (HAIR et al, 2009, p. 92).

Sobre o número mínimo de observações para aplicação da análise fatorial, Hair et al (2005) e Fávero et al (2009) afirmam que dificilmente se aplica análise fatorial com amostra abaixo de 50 observações, preferencialmente a amostra deve ser superior a 100 observações. Como regra geral utiliza-se um mínimo de 5 vezes mais observações do que o número de variáveis a serem analisadas, sendo recomendável 10 vezes mais observações que o número de variáveis. Entretanto, Fávero et al (2009) destaca que o dimensionamento amostral 
resguarda o pesquisador quanto ao número de observações para aplicação de técnicas multivariadas.

Por sua vez, Wolins (1995) afirma que não existe um tamanho de amostra mínimo para efetuar uma análise fatorial com um determinado número de variáveis. Para ele, é incorreto supor que estudos fatoriais que envolvem um grande número de variáveis requerem amostras maiores do que estudos com menos variáveis.

Como premissa para utilização de técnicas multivariadas, Fávero et al (2009) e Hair et al (2005) ressaltam a preocupação com a premissa da distribuição normal multivariada das variáveis. Fávero et al (2009) complementa afirmando que, para que a aplicação da análise fatorial seja adequada, deve-se observar três aspectos: análise da matriz de correlações, verificação da estatística de Kaiser-Meyer-Olkin (KMO) e teste de esfericidade de Bartlett.

Assim, primeiramente, verificou-se a normalidade multivariada das variáveis pelo teste de Doornik-Hansen, com resultado de 0,3510 para as variáveis referentes aos benefícios, e 0,0178 para as variáveis referentes aos desafios. Para verificar a adequação da aplicação da análise fatorial foram observadas as matrizes de correlação dos benefícios e desafios. A inspeção visual da matriz de correlação dos benefícios indicou 65,93\% de correlações acima de 0,30 , enquanto na matriz de correlação dos desafios foram identificadas $52,75 \%$ de correlações acima de 0,30. Portanto, o número substancial de correlações acima de 0,30 torna a aplicação da análise fatorial apropriada em ambos os casos.

Em seguida, foi aplicado o teste de esfericidade de Bartlett no conjunto de variáveis referentes a benefícios e no conjunto de variáveis referentes a desafios, obtendo p-value igual a 0 em ambos, o que significa que foi refutada a hipóteses de matriz com determinante igual a 0 e ausência de correlação entre as variáveis. Por fim, foi calculada a estatística KMO com resultado 0,825 para os benefícios e 0,717 para os desafios, resultados considerados como admirável e mediano, respectivamente, por Hair et al (2005). Com base nesses três testes, estabeleceu-se que a aplicação da análise fatorial é adequada para ambos os conjuntos de variáveis.

$\mathrm{Na}$ aplicação da análise fatorial, o método para obtenção de fatores escolhido foi a análise dos componentes principais (ACP), visto que o objetivo da pesquisa é redução dos dados para obtenção do menor número de fatores necessários para explicar o máximo de variância representada pelas variáveis originais. 


\section{BENEFÍCIOS E DESAFIOS NA IMPLANTAÇÃO DA AUDITORIA BASEADA EM RISCO EM \\ INSTITUIÇÕES FEDERAIS DE ENSINO \\ DOI: http://dx.doi.org/10.5007/1983-4535.2017v10n4p109}

Posteriormente, foi realizada a rotação dos fatores pelo método varimax na busca por minimizar o número de variáveis que têm altas cargas em um fator. $\mathrm{O}$ número de fatores foi determinado pelo critério de raiz latente, sendo selecionados os fatores com carga fatorial maior que 1. Desse modo, foram selecionados dois fatores para os benefícios da ABR e três fatores para os desafios da ABR. Num primeiro momento, cada variável foi alocada naquele fator em que apresentava maior carga fatorial.

Por fim, a confiabilidade dos fatores gerados foi medida para avaliar a consistência entre múltiplas medidas de cada uma das variáveis, por meio do alfa de Cronbach, sendo 0,70 o menor valor aceito para esta medida.

\section{RESULTADOS DA PESQUISA}

Incialmente são apresentados os resultados do tratamento estatístico dos dados do perfil dos indivíduos pesquisados. A idade dos respondentes foi verificada por meio de seis faixas etárias. A análise revelou que 51,97\% dos respondentes está na faixa etária de 30 a 39 anos, seguida por $23,62 \%$ na faixa etária de 40 a 49 anos, $13,38 \%$ na faixa etária de 50 a 59 anos, $10,24 \%$ na faixa etária de 20 a 29 anos e $0,79 \%$ na faixa etária a partir de 60 anos. A maioria dos respondentes $(74,02 \%)$ possui curso de especialização, 22,05\% possuem mestrado, 2,36\% possuem doutorado e apenas $1,57 \%$ \% possui apenas o curso de graduação.

A formação acadêmica dos respondentes concentra-se nos bacharelados em ciências contábeis $(40,94 \%)$, direito $(31,50 \%)$ e economia $(14,17 \%)$. Respondentes com formação em administração são apenas 7,09\%, e com outra formação são 6,30\%. A concentração deve ter ocorrido pela restrição a estas três áreas de formação para ingresso no cargo de auditor nas universidades federais e institutos federais, conforme Lei $\mathrm{n}^{\mathrm{o}} 11.091$, de 12 de janeiro de 2005 . Entretanto, o gestor público pode designar servidores ocupantes de outros cargos para atuarem nas unidades de auditoria interna. Constata-se que a maioria dos respondentes $(58,27 \%)$ exerce a função de auditor interno, 36,22\% são chefes da auditoria interna, $2,36 \%$ são assistentes de auditoria e 3,15\% ocupam outra função.

Quanto ao tempo de atuação na auditoria interna, a maioria dos respondentes $(65,35 \%)$ atua há mais de 3 anos na auditoria interna, sendo $42,52 \%$ de 5 a 10 anos, $18,90 \%$ de 3 a 5 anos e 3,93\% acima de 10 anos. A grande maioria dos respondentes $(86,61 \%)$ não possui qualquer certificação em auditoria interna. As certificações CIA, CGPA e CRMA aparecem 


\section{BENEFÍCIOS E DESAFIOS NA IMPLANTAÇÃO DA AUDITORIA BASEADA EM RISCO EM \\ INSTITUIÇÕES FEDERAIS DE ENSINO \\ DOI: http://dx.doi.org/10.5007/1983-4535.2017v10n4p109}

com $0,79 \%$ cada, enquanto $12 \%$ dos respondentes declararam possuir outras certificações, emitidas por entidades diferentes do IIA.

Tal resultado não pode ser interpretado como falta de qualificação dos integrantes das auditorias interna, visto que esta pesquisa não buscou identificar as capacitações e treinamentos realizados na área de auditoria interna, bem como a participação em eventos e congressos sobre o tema. Entretanto, permite afirmar que há grande oportunidade para investimento na qualificação dos integrantes de auditoria interna por meio de certificações internacionais, especialmente aquelas promovidas pelo IIA.

A grande maioria dos respondentes $(66,93 \%)$ avaliou o nível de maturidade em gestão de riscos de sua instituição como ingênuo, nível mais baixo de maturidade e correspondente a nenhuma abordagem formal desenvolvida para a gestão de risco. Outros 31,49\% avaliaram com o nível consciente, enquanto $0,79 \%$ avaliou com o nível definido, e $0,79 \%$ com o nível gerenciado.

A grande maioria dos respondentes $(73,23 \%)$ afirmou que ainda não foi implantada gestão de riscos na instituição, enquanto 14,96\% apontam que a implantação ocorreu há menos de 1 ano. Apenas 8,66\% dos respondentes afirmam que a implantação da gestão de riscos na instituição ocorreu há mais de 1 ano.

Esse resultado demonstra o quanto a gestão de riscos é ainda incipiente nos órgãos vinculados ao Ministério da Educação, visto que 88,19\% dos respondentes afirmou que foi implantada há menos de 1 ano ou ainda não foi implantada na sua instituição. Além disso, $66,93 \%$ dos respondentes afirmam que não há abordagem formal desenvolvida para a gestão de risco na instituição, visto que a inexistência de abordagem formal implica na ausência da gestão de riscos.

Quanto ao modelo de gestão de riscos utilizada pela instituição, 55,91\% dos respondentes afirmaram que nenhuma metodologia é utilizada e 11,02\% não souberam responder a questão. Dentre os modelos utilizados, recebe destaque o COSO I, com 23,62\%, seguido pelo COSO II, com 7,87\%, ISO 31000, com $0,79 \%$ e "outra metodologia", com 0,79\%. Os modelos FERMA e AS/NZS 4360, abordados no referencial teórico deste estudo, não foram citadas por nenhum respondente.

O resultado evidencia que $33,07 \%$ dos respondentes afirmam que sua instituição adota algum modelo de gestão de risco, enquanto apenas $23,62 \%$ dos respondentes afirmam que a gestão de riscos já foi implantada na instituição. A correlação destes resultados pode levar à 
hipótese de que algumas instituições já utilizam algum modelo de gestão de riscos em atividades específicas, mas ainda não avançaram para o passo seguinte de implantar formalmente a gestão de riscos no âmbito de toda a instituição.

A maioria dos respondentes $(59,84 \%)$ informou que a instituição anda não implantou a auditoria baseada em risco. Estes respondentes encerram a resposta do questionário nesta questão. Os outros 40,16\% afirmaram que a auditoria baseada em risco já foi implantada e, portanto, responderam cinco questões adicionais especificamente sobre auditoria baseada em risco.

O resultado de 59,84\% afirmarem não ter implantado a auditoria baseada em risco combinado ao resultado de $66,93 \%$ afirmarem que o nível de maturidade de gestão de riscos é ingênuo, corrobora com o entendimento de Griffiths (2005), Pommerening e Bencke (2011) e Pinho e Bezerra (2015) de que a ausência de um processo adequado de gestão de riscos na entidade dificulta a adoção da metodologia de auditoria baseada em risco.

Dentre os respondentes, $66,67 \%$ afirmam que a metodologia foi implantada há menos de 1 ano. Apenas 29,41\% dos respondentes afirmam que a implantação ocorreu entre 1 e 3 anos, enquanto 3,92\% apontam implantação há mais de 3 anos. Esse resultado constata o quão recente é a metodologia de auditoria baseada em riscos nos órgãos vinculados ao MEC.

Em relação ao efeito da implantação da auditoria baseada em riscos na aderência às normas internacionais de auditoria interna, 50,98\% dos respondentes afirmam que aumentou a aderência, enquanto $47,06 \%$ afirmam que a aderência às normas internacionais se manteve igual e 1,96 afirma que reduziu a aderência.

A análise das normas internacionais, que são focadas na governança corporativa, gestão de riscos e controle interno, cria expectativa de que a mudança da auditoria tradicional para a metodologia de auditoria baseada em riscos promoverá maior aderência às normas internacionais de auditoria, entretanto, tal expectativa não foi confirmada pelos resultados da pesquisa.

Por meio das analises, identificou-se que as atividades realizadas com maior frequência para implantação da auditoria baseada em risco são: elaboração de PAINT baseado em riscos $(94,11 \%)$, capacitação dos auditores internos $(60,78 \%)$, sensibilização dos gestores $(58,82 \%)$ e escolha da metodologia para pontuação dos riscos $(58,82 \%)$. As demais atividades tiveram frequência inferior a 50\%, com destaque para a contratação de consultoria especializada que não foi citada por nenhum respondente. 


\subsection{ANÁLISE DOS BENEFÍCIOS E DESAFIOS DA IMPLANTAÇÃO DA AUDITORIA BASEADA EM RISCO}

A técnica de análise fatorial foi aplicada em dois diferentes conjuntos de variáveis: benefícios na implantação da ABR e desafios na implantação da ABR. Desse modo, foram selecionados dois fatores para os benefícios da ABR e três fatores para os desafios da ABR.

Num primeiro momento, cada variável foi alocada naquele fator em que apresentava maior carga fatorial. A Tabela 1 apresenta as maiores cargas fatoriais de cada um dos dois fatores gerados para o conjunto de variáveis referente aos benefícios da implantação da ABR:

Tabela 1 Cargas fatoriais referentes aos benefícios de implantação da ABR

\begin{tabular}{|c|c|c|}
\hline \multicolumn{3}{|l|}{ Benefícios da auditoria baseada em riscos } \\
\hline Itens & Fator 1 & Fator 2 \\
\hline $\begin{array}{l}\text { 1-Auditorias tornam-se mais eficientes porque avaliam áreas de maior } \\
\text { risco }\end{array}$ & 0,5594 & \\
\hline 2-Enfoque top-down: do estratégico para o operacional & 0,5118 & \\
\hline 3-Conhecimento dos riscos da instituição & 0,6488 & \\
\hline 4-Conhecimentos dos controles internos & & 0,5212 \\
\hline 5-Menor atrito com os auditados & & 0,7867 \\
\hline 6-Melhor gerenciamento das recomendações & & 0,8736 \\
\hline 7-Relatórios de auditoria com melhor aceitação pela Alta Administração & & 0,7543 \\
\hline 8-Maior agregação de valor a instituição & 0,7577 & \\
\hline 9-Redução dos custos do trabalho da auditoria & & 0,5299 \\
\hline 10-Priorização de ações de auditoria nas atividades mais importantes & 0,4558 & \\
\hline 11-As respostas aos riscos tornaram-se mais eficazes & 0,6825 & \\
\hline 12-Fortalecimento da gestão de riscos da instituição & 0,8354 & \\
\hline 13-Maior aproximação com a Alta Administração & 0,6924 & \\
\hline $\begin{array}{l}\text { 14-Visão integrada da instituição em detrimento da visão } \\
\text { departamentalizada }\end{array}$ & 0,7175 & \\
\hline Variância explicada (\%) & 49,14 & 39,84 \\
\hline
\end{tabular}

Fonte: Software STATA 12. Elaborado pelos autores (2016).

Para o conjunto de variáveis referente aos desafios da implantação da ABR foram gerados três fatores e suas maiores cargas fatoriais são apresentadas na Tabela 2 . 
Tabela 2 Cargas fatoriais referentes aos desafios de implantação da ABR

\begin{tabular}{l|c|c|c}
\hline \multicolumn{3}{c}{ Desafios da auditoria baseada em riscos } \\
\multicolumn{1}{c|}{ Itens } & $\begin{array}{c}\text { Fator } \\
\mathbf{1}\end{array}$ & $\begin{array}{c}\text { Fator } \\
\mathbf{2}\end{array}$ & $\begin{array}{c}\text { Fator } \\
\mathbf{3}\end{array}$ \\
\hline 1-Baixa maturidade de gestão de risco na instituição & & & 0,8762 \\
\hline 2-Ausência de modelo de gestão de riscos na instituição & & & 0,9038 \\
\hline 3-Redução da independência da auditoria interna & 0,6973 & & \\
\hline $\begin{array}{l}\text { 4-Ausência de instrumentos e papéis de trabalho específicos para o foco } \\
\text { em riscos }\end{array}$ & 0,7131 & & \\
\hline 5-Aderência às normas internacionais & 0,5668 & & \\
\hline 6-Capacitação técnica dos auditores internos & 0,4814 & & \\
\hline 7-Resistência a mudança pelos auditores internos & & 0,4173 & \\
\hline 8-Resistência a mudança pelos gestores & & 0,7667 & \\
\hline 9-Falta de apoio da Alta Administração & & 0,8236 & \\
\hline 10-Falta de envolvimento das pessoas interessadas & & 0,6972 & \\
\hline 11-Custos da implantação da Auditoria Baseada em Riscos & 0,5223 & & \\
\hline 12-Adequação a aspectos legais & 0,8636 & & \\
\hline 13-Adequação a normas internas & 0,7700 & & \\
\hline 14-Padronização nos trabalhos da equipe & 0,5876 & & \\
\hline Variância explicada (\%) & 39,15 & 26,94 & 21,78 \\
\hline
\end{tabular}

Fonte: Software STATA 12. Elaborado pelos autores (2016).

Quanto aos benefícios de implantação da ABR foram identificados dois fatores. $\mathrm{Na}$ composição do fator 1, optou-se por excluir a variável "10-Priorização de ações de auditoria nas atividades mais importantes", por ter carga fatorial abaixo de 0,50 e, consequentemente, não apresentar significância prática. A variância explicada pelo fator $1(49,14 \%)$ foi alta e a confiabilidade das variáveis foi confirmada por meio do cálculo do Alpha de Cronbach, com resultado igual a 0,8763 .

O fator 1 é composto por oito variáveis e a frequência com que o grau de importância de cada variável foi avaliado pelos respondentes está apresentada na Tabela 3: 
Tabela 3 Frequência de avaliação das variáveis do Fator 1 de benefícios

\begin{tabular}{l|c|c|c|c|c}
\hline \multicolumn{1}{c|}{ Variáveis } & $\begin{array}{c}\text { Nada } \\
\text { importante }\end{array}$ & Baixo & Razoável & Alto & $\begin{array}{c}\text { Muito } \\
\text { Alto }\end{array}$ \\
\hline $\begin{array}{l}\text { Auditorias tornam-se mais eficientes porque } \\
\text { avaliam áreas de maior risco }\end{array}$ & 1,96 & 1,96 & 33,34 & 52,94 & 9,80 \\
\hline $\begin{array}{l}\text { Ausência de modelo de gestão de riscos na } \\
\text { instituição }\end{array}$ & 3,92 & 13,73 & 47,06 & 25,49 & 9,80 \\
\hline $\begin{array}{l}\text { Conhecimento dos riscos da instituição } \\
\text { Maior agregação de valor a instituição }\end{array}$ & 0 & 19,61 & 39,22 & 29,41 & 11,76 \\
\hline $\begin{array}{l}\text { As respostas aos riscos tornaram-se mais } \\
\text { eficazes }\end{array}$ & 1,96 & $9,9,80$ & 43,14 & 39,22 & 5,88 \\
\hline $\begin{array}{l}\text { Fortalecimento da gestão de riscos da } \\
\text { instituição }\end{array}$ & 7,84 & 3,92 & 29,41 & 37,26 & 21,57 \\
\hline $\begin{array}{l}\text { Maior aproximação com a Alta } \\
\text { Administração }\end{array}$ & 5,88 & 5,88 & 43,14 & 27,45 & 17,65 \\
\hline $\begin{array}{l}\text { Visão integrada da instituição em detrimento } \\
\text { da visão departamentalizada }\end{array}$ & 5,88 & 9,80 & 33,34 & 37,26 & 13,72 \\
\hline
\end{tabular}

Fonte: Dados da coleta. Elaborado pelos autores (2016).

A maior parte dos componentes do fator 1 está relacionada à melhoria na gestão de riscos, assim como a variável com maior carga fatorial: fortalecimento da gestão de riscos da instituição $(0,8354)$. Portanto, o fator 1 pode ser identificado como consolidação da gestão de riscos.

Esse fator aborda a relação de mútuo aperfeiçoamento existente entre a gestão de riscos e ABR. Diversos autores citam que a existência de uma estrutura de gestão de riscos é pré-requisito para a implantação da $\mathrm{ABR}$, ao passo que os resultados desta pesquisa indicam que a implantação da $\mathrm{ABR}$ é um processo que influencia positivamente a consolidação da gestão de riscos nas instituições.

O fator 2 tem variância explicada de $39,84 \%$ e é composto por cinco variáveis. A confiabilidade das variáveis foi confirmada por meio do cálculo do Alpha de Cronbach, com resultado igual a 0,8267 . O fator 2 é composto por cinco variáveis e a frequência com que o grau de importância de cada variável foi avaliado pelos respondentes está apresentada na Tabela 4: 
Tabela 4 Frequência de avaliação das variáveis do Fator 2 de benefícios

\begin{tabular}{l|c|c|c|c|c}
\hline \multicolumn{1}{c|}{ Variáveis } & $\begin{array}{c}\text { Nada } \\
\text { importante }\end{array}$ & Baixo & Razoável & Alto & $\begin{array}{c}\text { Muito } \\
\text { Alto }\end{array}$ \\
\hline Conhecimentos dos controles internos & 0 & 19,61 & 39,22 & 29,41 & 11,76 \\
\hline Menor atrito com os auditados & 7,84 & 23,53 & 39,22 & 19,61 & 9,80 \\
\hline Melhor gerenciamento das recomendações & 5,88 & 21,57 & 43,14 & 23,53 & 5,88 \\
\hline $\begin{array}{l}\text { Relatórios de auditoria com melhor } \\
\text { aceitação pela Alta Administração }\end{array}$ & 1,96 & 15,69 & 37,25 & 27,45 & 17,65 \\
\hline Redução dos custos do trabalho da auditoria & 15,69 & 19,61 & 49,02 & 7,84 & 7,84 \\
\hline
\end{tabular}

Fonte: Dados da coleta. Elaborado pelos autores (2016).

Três das variáveis componentes deste fator tratam das etapas finais do processo de auditoria: comunicação e monitoramento. Esse resultado demonstra que a ABR tem maior influência positiva nas etapas de comunicação e monitoramento de auditoria que nas etapas de planejamento e execução de auditoria. Por esse motivo, o fator é denominado como aperfeiçoamento na comunicação e monitoramento das auditorias.

A partir da análise fatorial, o Quadro 1 demonstra a composição dos fatores referentes aos benefícios da implantação da ABR.

Quadro 1 Composição dos fatores de benefícios da implantação da ABR

\begin{tabular}{|c|c|}
\hline Fatores & Componentes \\
\hline \multirow{8}{*}{$\begin{array}{l}\text { Consolidação da } \\
\text { gestão de riscos }\end{array}$} & $\begin{array}{l}\text { Auditorias tornam-se mais eficientes porque avaliam áreas de maior } \\
\text { risco }\end{array}$ \\
\hline & Enfoque top-down: do estratégico para o operacional \\
\hline & Conhecimento dos riscos da instituição \\
\hline & Maior agregação de valor a instituição \\
\hline & As respostas aos riscos tornaram-se mais eficazes \\
\hline & Fortalecimento da gestão de riscos da instituição \\
\hline & Maior aproximação com a Alta Administração \\
\hline & $\begin{array}{l}\text { Visão integrada da instituição em detrimento da visão } \\
\text { departamentalizada }\end{array}$ \\
\hline \multirow{5}{*}{$\begin{array}{l}\text { Aperfeiçoamento da } \\
\text { comunicação e } \\
\text { monitoramento de } \\
\text { auditorias }\end{array}$} & Conhecimentos dos controles internos \\
\hline & Menor atrito com os auditados \\
\hline & Melhor gerenciamento das recomendações \\
\hline & $\begin{array}{l}\text { Relatórios de auditoria com melhor aceitação pela Alta } \\
\text { Administração }\end{array}$ \\
\hline & Redução dos custos do trabalho da auditoria \\
\hline
\end{tabular}

Fonte: Elaboração própria (2016)

Para os desafios na implantação da ABR foram gerados três fatores. Na composição do fator 1, optou-se por excluir a variável "Capacitação técnica dos auditores internos", por ter carga fatorial abaixo de 0,50 e, consequentemente, não apresentar significância prática. A 
variância explicada pelo fator $1(39,15 \%)$ foi alta e a confiabilidade das variáveis foi confirmada por meio do cálculo do Alpha de Cronbach com resultado igual a 0,8631.

O fator 1 é composto por sete variáveis e a frequência com que o grau de importância de cada variável foi avaliado pelos respondentes está apresentada na Tabela 5:

Tabela 5 Frequência de avaliação das variáveis do Fator 1 de desafios

\begin{tabular}{l|c|c|c|c|c}
\hline \multicolumn{1}{c|}{ Variáveis } & $\begin{array}{c}\text { Nada } \\
\text { importante }\end{array}$ & Baixo & Razoável & Alto & $\begin{array}{c}\text { Muito } \\
\text { Alto }\end{array}$ \\
\hline $\begin{array}{l}\text { Redução da independência da auditoria } \\
\text { interna }\end{array}$ & 29,41 & 21,57 & 33,34 & 11,76 & 3,92 \\
\hline $\begin{array}{l}\text { Ausência de instrumentos e papéis de } \\
\text { trabalho específicos para o foco em riscos }\end{array}$ & 11,76 & 21,57 & 27,45 & 25,49 & 13,73 \\
\hline Aderência às normas internacionais & 3,92 & 31,37 & 35,30 & 21,57 & 7,84 \\
\hline $\begin{array}{l}\text { Custos da implantação da Auditoria Baseada } \\
\text { em Riscos }\end{array}$ & 17,65 & 29,41 & 31,37 & 21,57 & 0 \\
\hline Adequação a aspectos legais & 13,73 & 19,61 & 52,94 & 9,80 & 3,92 \\
\hline Adequação a normas internas & 13,73 & 19,61 & 45,09 & 17,65 & 3,92 \\
\hline Padronização nos trabalhos da equipe & 1,96 & 29,41 & 49,02 & 11,76 & 7,84 \\
\hline
\end{tabular}

Fonte: Dados da coleta. Elaborado pelos autores (2016).

A maior parte dos componentes do fator 1 está relacionada a questões normativas, assim como a variável com maior carga fatorial: adequação a aspectos legais $(0,77)$. Portanto, o fator 1 pode ser identificado como aspectos normativos. Esse resultado pode ser considerado surpreendente, visto que um dos principais objetivos da implantação da ABR é o atendimento às normas internacionais de auditoria interna.

Para o fator 2, optou-se por excluir a variável "Capacitação técnica dos auditores", com carga fatorial abaixo de 0,50 e sem significância prática. Dessa forma, o fator 2 tem variância explicada de $26,94 \%$ e é composto por três variáveis. A confiabilidade das variáveis foi confirmada por meio do cálculo do Alpha de Cronbach, com resultado igual a 0,8441.

O fator 1 é composto por sete variáveis e a frequência com que o grau de importância de cada variável foi avaliado pelos respondentes está apresentada na Tabela 6:

Tabela 6 Frequência de avaliação das variáveis do Fator 2 de desafios

\begin{tabular}{l|c|c|c|c|c}
\hline \multicolumn{1}{c|}{ Variáveis } & $\begin{array}{c}\text { Nada } \\
\text { importante }\end{array}$ & Baixo & Razoável & Alto & $\begin{array}{c}\text { Muito } \\
\text { Alto }\end{array}$ \\
\hline Resistência a mudança pelos gestores & 1,96 & 13,73 & 35,29 & 29,41 & 19,61 \\
\hline Falta de apoio da Alta Administração & 5,88 & 25,49 & 37,25 & 17,65 & 13,73 \\
\hline $\begin{array}{l}\text { Falta de envolvimento das pessoas } \\
\text { interessadas }\end{array}$ & 0 & 13,73 & 56,86 & 19,61 & 9,80 \\
\hline
\end{tabular}

Fonte: Dados da coleta. Elaborado pelos autores (2016). 
Todos os componentes do fator 2 são relacionados ao comportamento negativo de indivíduos quanto à mudança para uma metodologia de auditoria baseada em riscos. A maior carga fatorial foi atribuída à falta de apoio da alta administração e, portanto, o fator 2 pode receber esta denominação.

O fator 3 é aquele que apresenta maior confiabilidade, com resultado do Alfa de Cronbach igual a 0,9395. Conforme a Tabela 7, é composto por apenas duas variáveis relacionadas à fragilidade na estrutura de gestão de risco da instituição, e pode ser denominado como estrutura de gestão de riscos inadequada.

Tabela 7 Frequência de avaliação das variáveis do Fator 3 de desafios

\begin{tabular}{|c|c|c|c|c|c|}
\hline Variáveis & $\begin{array}{c}\text { Nada } \\
\text { importante }\end{array}$ & Baixo & Razoável & Alto & $\begin{array}{c}\text { Muito } \\
\text { Alto }\end{array}$ \\
\hline $\begin{array}{l}\text { Baixa maturidade de gestão de risco na } \\
\text { instituição }\end{array}$ & 0 & 9,80 & 17,65 & 27,45 & 45,10 \\
\hline $\begin{array}{l}\text { Ausência de modelo de gestão de riscos na } \\
\text { instituição }\end{array}$ & 1,96 & 9,80 & 15,69 & 33,33 & 39,22 \\
\hline
\end{tabular}

Fonte: Dados da coleta. Elaborado pelos autores (2016).

As dificuldades relacionadas à estrutura de gestão de risco muitas vezes impossibilitam a implantação da ABR nas organizações, enquanto em outras oportunidades apresentam-se como grandes dificuldades a serem superadas (GRIFFITHS, 2005, POMMERENING; BENCKE, 2011; PINHO; BEZERRA, 2015).

\section{CONSIDERAÇÕES FINAIS}

Essa pesquisa teve como objetivo realizar um diagnóstico acerca dos benefícios e desafios na implantação da ABR nas IFES brasileiras. Por meio do diagnóstico realizado, constatou-se que a gestão de riscos é tema ainda recente no contexto da gestão pública universitários, portanto, há potencial para incentivar e promover a cultura de gestão de riscos visando à modernização da administração pública brasileira.

A partir da identificação dos benefícios e desafios da implantação da ABR nas IFES, foi possível realizar tratamento estatístico dos dados por meio da técnica de análise fatorial. Do resultado da análise foram extraídos dois fatores que constituem benefícios da implantação da ABR e três fatores que constituem desafios neste processo de implantação.

Os fatores de benefícios da implantação da ABR foram denominados "Consolidação da gestão de riscos" e "Aperfeiçoamento da comunicação e monitoramento de auditorias". Os 
fatores de desafios no processo de implantação foram denominados "Aspectos normativos", "Falta de apoio da alta administração" e "Estrutura de gestão de riscos inadequada".

De uma forma geral, acredita-se que esses resultados podem contribuir com a implantação da ABR nas IFES, ajudando a criar valor para todas as partes interessadas, em particular, para a sociedade brasileira.

Como sugestões para novas pesquisas, pode ser verificada a percepção das pessoas auditadas quanto à abordagem adotada pela metodologia ABR, objetivando identificar se os auditados confirmam os benefícios citados pelos auditores internos nesta pesquisa.

\section{REFERÊNCIAS}

ABRUCIO, F. L. Trajetória recente da gestão pública brasileira: um balanço crítico e a renovação da agenda de reformas. Revista de Administração Pública, Rio de Janeiro, vol. 41, p. 67-86, 2007. Edição Especial Comemorativa.

ATTIE, W. Auditoria: conceitos e aplicações. 6. ed. São Paulo: Atlas, 2011.

BENLI, V. F.; CELAYIR, D. Risk based internal auditing and risk assessment process. European Journal of Accounting and Finance Research. Gillingham, v. 2, n. 7, p. 1-16, set. 2014.

BORGES, G. R.; DIEL, F. J.; FERNANDES, F. C. A contribuição da auditoria interna de riscos para o planejamento de organizações na área de saúde. Revista de Gestão em Sistemas de Saúde, São Paulo, v. 4, n 2, jul./dez. 2015.

BOYNTON, W. C.; JOHNSON, R. N.; KELL, W. G. Auditoria. São Paulo: Atlas, 2002.

BRASIL. Decreto-Lei no 200 de 25 de fevereiro de 1967. Dispõe sobre a organização da Administração Federal, estabelece diretrizes para a Reforma Administrativa e dá outras providências.

. Instrução Normativa ${ }^{\circ} 24$ de 17 de novembro de 2015. Dispõe sobre o Plano Anual de Auditoria Interna (PAINT), os trabalhos de auditoria realizados pelas unidades de auditoria interna e o Relatório Anual de Atividades da Auditoria Interna (RAINT) e dá outras providências.

Instrução Normativa Conjunta $n^{\circ} 01$ de 10 de maio de 2016. Dispõe sobre controles internos, gestão de riscos e governança no âmbito do Poder Executivo federal.

BRESSER PEREIRA, L. C. Administração pública gerencial: estratégia e estrutura para um novo estado. Brasília: Enap, 2001. 
CASTRO, D. P. Auditoria e controle interno na administração pública: evolução do controle interno no Brasil do código de contabilidade de 1922 até a criação da CGU em 2003.. São Paulo: Atlas, 2008.

CICCO, F. Auditoria Baseada em Riscos - Como implementar a ABR nas organizações: uma abordagem inovadora. São Paulo: Risk Tecnologia, 2007.

COLOMBRO; RODRIGUES. Desafios da Gestão Universitária Contemporânea. Porto Alegre: Artmed, 2011.

CREPALDI, S. A. Auditoria Contábil: teoria e prática. 3. ed. São Paulo: Atlas, 2009.

FÁVERO, L. P.; BELFIORE, P.; SILVA, F. L.; CHAN, B. L. Análise de dados: modelagem multivariada para tomada de decisões. Rio de Janeiro: Elsevier, 2009.

GRIFFITHS, P. Risk-Based Auditing. Burlington: Gower, 2005.

HAIR, J. F.; BABIN, B.; MONEY, A. H.; SAMOUEL, P. Fundamentos de Métodos de Pesquisa em Administração. Porto Alegre: Bookman, 2005.

IIA. Standards for the Professional Practice of Internal Auditing. Altamonte Spring, Florida: IIA, 2013.

KARAGIORGOS, T.; DROGALAS, G.; EFEFTHERIADIS, I.; CHRISTODOULOU, P. Internal audit contribution to eficiente risk management. Journal of Business Management. New Delhi, v. 2, n. 1, p. 1-14, jan./jun. 2010.

MADEIRA, J. E. M. A implantação das metodologias de auditoria baseadas em processo e em riscos: um estudo de caso no Banco do Nordeste do Brasil. 2010. 152 f. Dissertação (Mestrado Profissional em Adinistração e Controladoria) - Faculdade de Economia, Administração, Atuária e Contabilidade, Universidade Federal do Ceará, Fortaleza, 2010.

MARTINS, G. A; THEÓPHILO, C. R. Metodologia da Investigação Científica para Ciências Sociais Aplicadas. 2. ed. São Paulo: Atlas, 2009.

MCNAMEE, D.; SELIM, G. Risk Management: Changing the Internal Auditor' s Paradigm. Altamonte Spring, Florida: Institute of Internal Auditors Research Foundation, 1998.

MOELLER, R. Brinks's Modern Internal Auditing. New Jersey: John Willey \& Sons, 2009.

PICKETT, K. H. S. The essential handbook of internal auditing. Chichester: John Willey \& Sons, 2005.

PINHO, R. C. S.; BEZERRA, L. B. Implantação da auditoria baseada em risco em uma entidade do "sistema $S$ ": o caso do SEBRAE/CE. Revista Ambiente Contábil, v. 7, n. 2, p. 32-52, jul./dez. 2015. 
POMMERENING, E. J.; BENCKE, F. F. Auditoria convencional e a auditoria baseada em risco: contribuições à gestão organizacional. Unoesc \&Ciência - ACSA, Joaçaba, v. 2, n. 1, p. 15-26, jan./jun. 2011.

RAMAMOORTI, S. Research Opportunities in Internal Auditing. Chapter 1 - Internal Auditing: History, Evolution, and Prospects. Altamonte Spring, Florida: Institute of Internal Auditors Research Foundation, 2003.

SÁ, A. L. Curso de Auditoria. 10. ed. São Paulo: Atlas, 2002.

WOLINS, L. A Monte Carlo Study of Constrained Factor Analysis Using Maximum Likelihood and Unweighted Least Squares. Educational and Psychological Measurement, v. 55 , n. 4 , set. 1995. 